\title{
Artikel
}

\section{Uitbreiding WGBH/CZ met goederen en diensten}

\section{Rechtsbescherming van personen met een handicap neemt toe}

\author{
Mr. C.A. Goudsmit*
}

\section{Inleiding}

Volledige en volwaardige participatie en persoonlijke autonomie is de doelstelling van het Internationaal Verdrag inzake de Rechten van Personen met een Handicap (hierna: IVRPH ${ }^{1}$ ), dat voor Nederland op 14 juli 2016 in werking is getreden. ${ }^{2}$ Het College voor de Rechten van de Mens is aangewezen om op de naleving van het IVRPH in Nederland toe te zien. Alhoewel het IVRPH geen nieuwe rechten in het leven roept,${ }^{3}$ leidt de implementatie ervan wel degelijk tot een grotere rechtsbescherming van personen met een beperking. ${ }^{4}$ Immers, ter uitvoering van het IVRPH is met ingang van 14 juni 2016 de Wet gelijke behandeling op grond van handicap of chronische ziekte (WGBH/CZ) gewijzigd. ${ }^{5}$ Deze wijziging houdt in dat personen met een beperking thans ook de bescherming van deze wet kunnen inroepen in

* Mr. C.A. (Stans) Goudsmit is lid van het College voor de Rechten van de Mens. Met dank aan Annejet Swarte voor haar hulp bij de totstandkoming van dit artikel.

1. In het spraakgebruik wordt ook gebruikt: VN Verdrag Handicap.

2. Trb. 2007, 169 en Trb. 2014, 113

Kamerstukken I/ 2013/14, 33992 (R2034), 3.

4. Alhoewel het Verdrag spreekt over personen met een handicap, gebruiken we in Nederland het begrip 'beperking'. Dat laatste gaat niet uit van een medisch maar van een sociaal begrip, waarbij de interactie met de fysieke en sociale omgeving vooropstaat.

5. Stb. 2016, 215. Naast de WGBH/CZ wordt met deze uitvoeringswet ook de Kieswet, de Wet maatschappelijke ondersteuning 2015, de Jeugdwet en de participatiewet aangepast aan het IVRPH. geval van discriminatie op het terrein van goederen en diensten. Over deze uitbreiding gaat dit artikel.

\section{Uitbreiding van terreinen in de WGBH/CZ}

De gelijkebehandelingswetgeving biedt verschillende niveaus van bescherming tegen discriminatie door aanbieders van goederen en diensten. De Algemene wet gelijke behandeling (AWGB) strekt zich in artikel 7 reeds uit tot het brede terrein van goederen en diensten. Dat betekent dat een persoon die zich op dit terrein gediscrimineerd voelt op grond van godsdienst, levensovertuiging, politieke gezindheid, ras, geslacht, nationaliteit, hetero- of homoseksuele gerichtheid of burgerlijke staat, bescherming aan deze wet kan ontlenen. Ten aanzien van de grond leeftijd is deze bescherming er (nog) niet. ${ }^{6}$ De Wet gelijke behandeling op grond van leeftijd bij de arbeid (WGBL) beperkt zich tot arbeid en beroepsonderwijs. Dat betekent dat het nog steeds niet mogelijk is te klagen over leeftijdsdiscriminatie op het terrein van goederen en diensten. Datzelfde gold tot 14 juni 2016 ten aanzien van de grond handicap / chronische ziekte. Tot die datum beperkte de reikwijdte van de WGBH/CZ zich, naast arbeid, tot de diensten onderwijs (alleen het basis-, voorgezet en beroepsonder-

6. Daarvoor is het nodig dat eerst overeenstemming op Europees niveau wordt bereikt over de zogenoemde Europese Brede Richtlijn Gelijke Behandeling (COM (2008)426 def, 2008/0140 (CNS)), waarin o.a. deze uitbreiding is beoogd. Dat proces ligt echter stil. 
wijs), wonen en het openbaar vervoer. ${ }^{7}$ Dat betekende dat het College niet bevoegd was om te beoordelen of o.a. een telefonieaanbieder verboden onderscheid maakte door een korting alleen per telefoon en niet per chatbericht aan te bieden aan een doof persoon; of een organisator van cruisereizen verboden onderscheid maakte door maximaal twee personen met een handicap per reis mee te nemen; of een pretpark verboden onderscheid maakte door een kind met het syndroom van Down niet tot een attractie toe te laten. ${ }^{8}$

De WGBH/CZ is er in 2003 gekomen ter implementatie van de Europese Kaderrichtlijn ${ }^{9}$. De wet ging op dat moment niet verder dan het terrein van de arbeid en het beroepsonderwijs. De terreinen wonen, primair en voortgezet onderwijs en openbaar vervoer zijn respectievelijk per 15 maart 2009, 1 augustus 2009 en 9 mei 2012 aan de wet toegevoegd. $\mathrm{Nu}$ wordt ter implementatie van artikel 5 IVRPH, dat een algemene non-discriminatiebepaling omvat, de reikwijdte van de $\mathrm{WGBH} / \mathrm{CZ}$ gelijkgetrokken met de AWGB: de WGBH/CZ is thans ook van toepassing op het brede terrein van goederen en diensten. Dit is bepaald in artikel 5b WGBH/CZ.

De WGBH/CZ geldt, evenals de overige gelijkebehandelingswetgeving, in horizontale verhoudingen: die tussen werkgever en werknemer, tussen aanbieder van goederen en diensten en zijn klanten. De overheid die zich als zodanig gedraagt, valt ook onder de reikwijdte van de wet. Eenzijdig overheidshandelen is nog steeds van de werking van de wet uitgesloten. ${ }^{10}$ Dat betekent overigens niet dat een burger de overheid niet voor de rechter op discriminatoir eenzijdig overheidshandelen kan aanspreken. In de memorie van toelichting bij de goedkeuringswet is immers bevestigd dat het discriminatieverbod zoals vastgelegd in artikel 5 , lid 1 en 2 , van het IVRPH rechtstreekse werking heeft. ${ }^{11}$

\section{- Ten aanzien van ondermijs ${ }^{12}$}

Beperkte de WGBH/CZ zich in de artikelen $5 \mathrm{~b}$ en 6 tot basis-, voorgezet en beroepsonderwijs, de huidige WGBH/CZ ziet op het gehele onderwijsterrein: alle instellingen die werkzaam zijn op het gebied van het onderwijs zijn normadressaat; zie het huidige artikel 5b, sub c, WGBH/CZ. Deze uitbreiding duidt erop dat het College thans ook kan oordelen over discriminatie in het

7. Zie de artikelen $5 \mathrm{~b} t / \mathrm{m} 8 \mathrm{WGBH} / \mathrm{CZ}$ (oud).

8. Deze voorbeelden zijn ontleend aan vragen die het College via de Front Office binnen heeft gekregen.

9. Richtlijn 2000/78/EG van 27 november 2000 , tot instelling van een algemeen kader voor gelijke behandeling in arbeid en beroep.

10. Zie Kamerstukken I/ 2013/14, 33990, 3, p. 8.

11. Kamerstukken I/ 2013/14, 33992 (R2034), 3, p. 25. Art. 5, lid 1, VN Verdrag Handicap bepaalt dat de lidstaten 'erkennen dat eenieder gelijk is voor de wet en zonder aanziens des persoons recht heeft op dezelfde bescherming door, en hetzelfde voordeel van de wet'; lid 2 bepaalt dat de lidstaten 'verbieden alle discriminatie op grond van handicap en garanderen personen met een handicap op voet van gelijkheid effectieve wettelijke bescherming tegen discriminatie op welke grond dan ook.'

12. Zie ook het artikel van J. Schoonheim op p. 9-14 van dit nummer. speciaal onderwijs, waaronder de verplichting doeltreffende aanpassingen te verrichten. ${ }^{13}$

De uitbreiding van de WGBH/CZ naar het gehele onderwijsveld is van groot belang voor de inclusie van mensen met een beperking, nu uit onderzoek blijkt dat deze groep ten opzichte van de algemene bevolking op dit terrein - en ook op andere terreinen zoals betaald werken en zelfstandig wonen - op achterstand staat. Zo hebben kinderen met een beperking een grotere kans op thuiszitten en op voortijdig schoolverlaten, en gaat een aanzienlijk deel van deze kinderen naar het speciaal basis- en voortgezet onderwijs. Van inclusief onderwijs, dat in artikel 24 van het IVRPH is vastgelegd, is dan geen sprake. ${ }^{14}$

\section{- Ten aanzien van monen en openbaar vervoer}

Wonen en openbaar vervoer zijn ook na de wetsuitbreiding apart in de WGBH/CZ opgenomen. De betreffende artikelen $6 a$ tot en met $8 \mathrm{WGBH} / \mathrm{CZ}$ zijn ongewijzigd gebleven. Wonen blijft apart vermeld om zo de uitzondering in artikel $6 \mathrm{c}$ te kunnen handhaven, dat de verplichting om doeltreffende aanpassingen te verrichten niet van toepassing is indien het om bouwkundige of woontechnische aanpassingen gaat. De verplichting om deze laatste aanpassingen te verrichten kan op grond van de Wmo bij de gemeente liggen en kan niet worden afgewenteld op de huisvestingssector. Openbaar vervoer blijft apart benoemd omdat ook daar, op grond van artikel 8 , lid 2, WGBH/CZ, in aparte regelingen ${ }^{15}$ bepalingen over onder meer de te verrichten aanpassingen zijn opgenomen. ${ }^{16}$

Door de uitbreiding vallen ook andere vormen van vervoer, zoals touringcarvervoer, taxivervoer en lucht- en scheepvaart, onder het bereik van de wet. ${ }^{17}$

\section{- $\quad$ Overig aanbod van goederen en diensten}

Naast bovengenoemde categorieën noemt de memorie van toelichting bij de Uitvoeringswet voorbeelden van wat nog meer onder goederen en diensten kan vallen: detailhandel, horeca, cultuur, sport, recreatie, zakelijke dienstverlening, zorg en internetdiensten. ${ }^{18}$ Bij zakelijke dienstverlening kan gedacht worden aan o.a. financiële dienstverlening en verzekeringen. Opmerkelijk is dat in de memorie van toelichting ook de openbare ruimte onder het aanbod van goederen en diensten wordt geschaard. ${ }^{19}$ Opmerkelijk, omdat het de overheid is die de openbare ruimte inricht en beheert en eenzijdig overheidshandelen is juist van de werking van de wet uitgesloten. De rechter of het College voor de Rechten van de

13. Het College kon al wel oordelen over het speciaal basisonderwijs, omdat dit valt onder de Wet op het Primair Onderwijs en deze wet expliciet genoemd werd in art. 5b WGBH/CZ (oud).

14. Zie College voor de Rechten van de Mens, 'Inzicht in Inclusie. Werk, wonen en onderwijs: participatie van mensen met een beperking', 14 juli 2016, p. 36-40.

15. Besluit toegankelijkheid openbaar vervoer en Regeling toegankelijkheid openbaar vervoer.

16. Kamerstukken // 2013/14, 33990, 3, p. 6

17. Kamerstukken I/ 2013/14, 33992 (R2034), 3, p. 35.

18. Kamerstukken // 2013/14, 33990, 3, p. 5.

19. Kamerstukken // 2013/14, 33990, 3, p. 8. 
Mens zal deze bevoegdheidsvraag moeten beantwoorden.

\section{Discriminatieverbod}

Het discriminatieverbod, zoals thans neergelegd in artikel 5b, lid 1, WGBH/CZ, houdt in dat anbieders van goederen en diensten bij het anbieden daarvan ${ }^{20}$ geen verboden onderscheid mogen maken ten aanzien van personen met een beperking. $\mathrm{Zij}$ mogen hen vanwege hun beperking niet uitsluiten van diensten of benadelen, en ook niet discriminatoir bejegenen. In artikel 3 WGBH/CZ is een antal uitzonderingen op het discriminatieverbod neergelegd. Zo geldt het verbod van onderscheid onder andere niet als het onderscheid noodzakelijk is ter bescherming van de veiligheid en gezondheid. ${ }^{21}$

Onder het aanbieden van goederen valt niet het ontwerpen en produceren ervan. Het is volgens de regering al snel een onevenredige belasting voor een producent als die op verzoek van een persoon de productie moet aanpassen. De regering laat het aan de producenten zelf of, en zo ja op welke wijze, zij willen inspelen op de wensen van mensen met (en zonder) een beperking. ${ }^{22}$ Dit sluit aan bij eerdere oordelen van het College over het de reikwijdte van de AWGB: een producent heeft de vrijheid om te bepalen melke goederen hij produceert, inkoopt en/of aanbiedt. Het discriminatieverbod beperkt zich tot de wijze waarop dat aanbod wordt gedaan: dat aanbod moet voor iedereen openstaan. ${ }^{23}$ Overigens rust op de overheid op grond van artikel 4, lid 1, sub f, IVRPH wel een verplichting om de ontwikkeling van 'universeel ontwerp' van goederen en diensten te bevorderen. Met de opmerking dat 'design for all' iets is dat vooral vanuit de producenten zelf moet komen en waaraan in het kader van zelfregulering verder kan worden gewerkt, ${ }^{24}$ lijkt de regering an deze verplichting voorbij te gaan.

De wijziging van de WGBH/CZ heeft geen terugwerkende kracht. Echter, op grond van Aanwijzing 166, lid 1, Aanwijzingen voor de regelgeving ${ }^{25}$ geldt dat een nieuwe regeling niet slechts van toepassing is op hetgeen na haar inwerkingtreding voorvalt maar ook op 'hetgeen bij haar inwerkingtreding bestaat, zoals bestaande rechtsposities en verhoudingen (onmiddellijke werking)'. Dat kan betekenen dat een rechtsverhouding die voor deze wijziging van de $\mathrm{WGBH} / \mathrm{CZ}$ tot stand is

20. Art. 5, lid 1, WGBH/CZ spreekt over 'het aanbieden van of verlenen van toegang tot goederen en diensten en bij het sluiten, uitvoeren of beëindigen van overeenkomsten ter zake, alsmede bij het geven van loopbaanoriëntatie en advies of voorlichting over school- of beroepskeuze'.

21. Zie o.a. oordeel 2015-135 en 2016-46. Deze oordelen gingen over een afwijzing voor een functie. In beide gevallen oordeelde het College dat een beroep op de uitzondering niet opging

22. Kamerstukken I/ 2013/14, 33990, 6, p. 10.

23. Zie bijvoorbeeld oordeel 2010-32.

24. Kamerstukken I/ 2013/14, 33990, 3, p. 9

25. Stcrt. 1992, 230; laatstelijk gewijzigd bij Stcrt. 2011, 6602. gekomen en tot op heden voortduurt, bijvoorbeeld die tussen een verzekeraar en een verzekerde met een beperking, toch onder de werking van de huidige WGBH/CZ valt. Discriminatoire bepalingen daarin, bijvoorbeeld het heffen van een hogere premie vanwege de handicap, kunnen dan alsnog ter toetsing aan het College worden voorgelegd. Deze lijn nam het College ook aan bij de inwerkingtreding van de WGBL. ${ }^{26}$ Een weigering van voor 14 juni 2016 om een verzekering af te sluiten vanwege een handicap kan niet ter toetsing worden voorgelegd.

\subsection{Doeltreffende aanpassingen}

Voor de inclusie van mensen met een beperking is van groot belang dat met de uitbreiding van de WGBH/CZ op aanbieders van goederen en diensten nu ook de verplichting rust om in het individuele geval doeltreffende aanpassingen te treffen. Dit is neergelegd in artikel 2 WGBH/CZ.

De verplichting tot het treffen van doeltreffende aanpassingen is in de wet opgenomen om personen met een handicap of chronische ziekte in individuele gevallen in staat te stellen deel te (blijven) nemen aan het maatschappelijk leven, indien die deelname wordt bedreigd door de wijze waarop o.a. het aanbod van goederen en diensten is ingericht. Op grond van deze norm rust op aanbieders de verplichting om desgevraagd belemmeringen weg te nemen. In de wetsgeschiedenis wordt genoemd dat mensen met een lichamelijke of visuele beperking vooral de fysieke toegankelijkheid als belemmering zien; voor mensen met een psychische beperking is dat het ontbreken van duidelijkheid of een grote hoeveelheid prikkels; voor mensen met een auditieve beperking vooral storende omgevingsgeluiden, slechte akoestiek en het ontbreken van grafische of leesbare informatie in de openbare ruimte; voor mensen met een verstandelijke beperking onduidelijkheid van communicatie en informatie; voor mensen met een chronische ziekte vooral gebrekkige informatievoorziening over de bestanddelen van diverse producten; voor alle mensen met een beperking de omgang, bejegening en service van het personeel. ${ }^{27}$

Gezien de veelheid aan belemmeringen zijn ook de mogelijke anpassingen talrijk. In de wetsgeschiedenis wordt een antal voorbeelden genoemd, zoals het uitleggen van een loopplank voor personen in een rolstoel om een winkel in te komen en het voorlezen van een menukaart in een restaurant voor een blinde persoon. ${ }^{28}$ Dit zijn eenvoudige en goedkope aanpassingen die passen in het uitgangspunt van de regering dat deze uitbreiding van de WGBH/CZ geen hoge kosten voor aanbieders van goederen en diensten met zich meebrengt. ${ }^{29}$ Het College heeft evenwel geoordeeld dat ook complexere of duurdere aanpassingen, zoals aanpassingen aan de werk-

26. Oordeel 2011-199, overweging 3.5-3.6.

27. Kamerstukken I/ 2013/14, 33990, 3, p. 6

28. Kamerstukken I/ 2013/14, 33990, 11, p. 4-5.

29. Twee jaar na inwerkingtreding zal worden bekeken of deze aanname juist is gebleken; Kamerstukken I/ 2013/14, 33990, 3, p. 3. 
plek of in het onderwijs, ${ }^{30}$ in het licht van de WGBH/ CZ als doeltreffende aanpassing kunnen gelden.

Het toelaten van assistentiehonden is met de huidige wetswijziging als enige expliciet als doeltreffende aanpassing in de wet opgenomen; zie artikel 2, lid 2, $\mathrm{WGBH} / \mathrm{CZ}$.

In de oordelen van het College voor de Rechten van de Mens is nader bepaald hoe ver de ex-nunc-verplichting van een aanbieder van goederen en diensten reikt om doeltreffende aanpassingen te verrichten. Zo hoeft een aanbieder niet op voorhand al doeltreffende aanpassingen te verrichten, zonder dat er een concrete behoefte is. Dat hoeft hij pas te doen als daar expliciet om wordt gevraagd. ${ }^{31}$ Ook hoeft een doeltreffende aanpassing niet precies datgene te zijn waar de persoon met een handicap om vraagt. Voorwaarde is dat de aanpassing doeltreffend is, te weten geschikt en noodzakelijk. ${ }^{32}$ Geschikt is een aanpassing als deze in staat is de belemmeringen weg te nemen en noodzakelijk houdt in dat er geen ander, goedkoper of minder ingrijpend, alternatief voor handen is. Dit leidt tot een plicht aan de kant van de aanbieder om, in overleg met degene die om een aanpassing vraagt, te onderzoeken welke aanpassing hieraan voldoet. Dat onderzoek moet tijdig worden uitgevoerd. Het nalaten of niet voortvarend uitvoeren van dit onderzoek is in strijd met de gelijkebehandelingswetgeving. ${ }^{33}$ Het IVRPH spreekt in artikel 5, lid 3 over 'redelijke aanpassingen' die moeten worden getroffen om discriminatie uit te bannen. $\mathrm{Nu}$ de regering van mening is dat dit begrip overeenkomt met het begrip 'doeltreffende aanpassingen' uit de WGBH/CZ, is deze laatste op dit punt dan ook niet aangepast. ${ }^{34}$

\subsection{Uitzondering op verplichting doeltreffende aanpassingen te verrichten}

Wanneer de te treffen doeltreffende aanpassingen een onevenredige belasting vormen voor de aanbieder, hoeft deze de aanpassingen niet te verrichten (artikel 2, lid 1, $\mathrm{WGBH} / \mathrm{CZ}$ ). Om vast te stellen of deze uitzondering van toepassing is, zullen de belangen van de persoon met een beperking moeten worden afgewogen tegen die van de aanbieder. Aan de kant van de aanbieder kunnen onder andere meewegen: de omvang en middelen van de organisatie, de geraamde kosten, de operationele en technische haalbaarheid van de aanpassing en de vraag of de betrokken aanpassing onuitvoerbaar of onveilig is. ${ }^{35}$ Het belang van de persoon met een beperking is er in gelegen om toegang te krijgen tot het goed of de dienst.

Bijvoorbeeld door een slechtziende een groot beeldscherm te verschaffen (oordeel 2014-138); door een-op-eenbegeleiding tijdens een schoolkamp voor een leerling die een hersenbloeding heeft gehad (oordeel 2013-152); door aanpassing van het rooster en een vaste begeleider voor een leerling met een chronische ziekte.

31. Oordeel 2015-148.

32. Oordelen 2016-6 en 2016-56.

33. Oordeel 2015-26; zie ook Kamerstukken I/ 2014/15, 33990, 6, p. 18.

34. Kamerstukken I/ 2013/14, 33990, 3, p. 7.

35. Kamerstukken I/ 2013/14, 33990, 3, p. 7 en 8; nr. 11, p. 4.
In de wetsgeschiedenis worden meerdere voorbeelden gegeven van aanpassingen die een onevenredige belasting kunnen vormen: ${ }^{36}$

- het verschaffen van een menukaart in braille voor iemand met een visuele beperking, waar het restaurant kan volstaan met het voorlezen van de menukaart;

- het installeren van een lift voor een persoon die slecht ter been is en een winkel wil binnengaan, waar kan worden volstaan met het bieden van een helpende hand;

- het installeren van een lift in een schoolgebouw voor een leerling in een rolstoel, waar kan worden volstaan met het aanpassen van het rooster zodat de lessen op de begane grond kunnen worden gevolgd.

Ten aanzien van deze voorbeelden moet wel worden opgemerkt dat het College of de rechter per geval bekijkt of de aanpassing daadwerkelijk onevenredig belastend is. Het College heeft hierover al een aantal malen geoordeeld. Zo achtte het College de installatie van een beveiligingssysteem middels infrarood ter vervanging van een weegmat ${ }^{37}$ en het aanschaffen van bedrijfskleding in de maat van een persoon met obesi$\operatorname{tas}^{38}$ vanwege de kosten onevenredig belastend.

\section{Algemene toegankelijkheid}

Naast de verplichting om desgevraagd doeltreffende aanpassingen voor een individu te treffen, wordt met de uitbreiding van de $\mathrm{WGBH} / \mathrm{CZ}$ voor aanbieders van goederen en diensten in artikel $2 \mathrm{a}$ ook de verplichting opgenomen om geleidelijk zorg te dragen voor de algemene toegankelijkheid voor personen met een handicap of chronische ziekte. Tenzij dat een onevenredige belasting vormt. De tekst van het nieuwe artikel 2a WGBH/ CZ luidt:

'1. Degene tot wie het verbod van onderscheid zich richt, draagt daarnaast tenminste geleidelijk zorg voor de algemene toegankelijkheid voor personen met een handicap of chronische ziekte, tenzij dat voor hem een onevenredige belasting vormt.

2. Onverminderd het bepaalde bij of krachtens enige wettelijke bepaling, worden bij algemene maatregel van bestuur regels gesteld ter uitvoering van het eerste lid. Deze regels hebben in ieder geval betrekking op de geleidelijke verwezenlijking van de algemene toegankelijkheid, op het treffen van voorzieningen van eenvoudige aard en op de evenredigheid van de belasting.

3. (...).' 
Toegankelijkheid is een van de grondbeginselen van het IVRPH ${ }^{39}$ en wordt gezien als een voorwaarde voor personen met een handicap om volwaardig in de samenleving te kunnen functioneren. Toegankelijkheid van onder meer informatie, communicatie en de fysieke omgeving is noodzakelijk om de materiële rechten uit het IVRPH op voet van gelijkheid te kunnen uitoefenen. Deze uitbreiding van de WGBH/CZ met algemene toegankelijkheid geldt, net als de verplichting om doeltreffende aanpassingen te verrichten, voor het gehele terrein van de WGBH/CZ: goederen en diensten, en ook arbeid, onderwijs, wonen en openbaar vervoer. Artikel 2a WGBH/CZ geldt nog niet en zal uiterlijk op 1 januari 2017 in werking treden. ${ }^{40}$

Deze uitbreiding naar een algemene toegankelijkheid, die middels een amendement in de wet terecht is gekomen, beoogt een verandering in het denken over toegankelijkheid voor mensen met een handicap: 'Toegankelijkheid moet normaal worden, ontoegankelijkheid wordt de uitzondering. ${ }^{41}$ Hoe toegankelijker de samenleving is, des te minder individuele doeltreffende aanpassingen er verricht hoeven te worden. ${ }^{42}$ De verplichting om zorg te dragen voor algemene toegankelijkheid is een ex-ante-verplichting, die, anders dan bij een doeltreffende aanpassing, niet pas ontstaat als een individu daarom vraagt. ${ }^{43}$ Omdat niet van een aanbieder van goederen en diensten verwacht kan worden dat hij direct optimaal toegankelijk is, is allereerst in artikel $2 \mathrm{a}$, lid 1 , WGBH/CZ een redelijkheidscriterium opgenomen: aanpassingen die onevenredig belastend zijn, hoeven niet te worden verricht. Daarnaast wordt dit ook onderstreept door de bewoording in lid 1 dat de aanbieder van goederen en diensten 'geleidelijk' zorg draagt voor algemene toegankelijkheid. Om duidelijkheid te scheppen over hoe ver de verplichting tot algemene toegankelijkheid reikt, is in artikel $2 \mathrm{a}$, lid 2, vastgelegd dat over de inhoud hiervan bij AMvB nadere regels gesteld moeten worden. ${ }^{44}$ Deze regels hebben in ieder geval betrekking op de geleidelijke verwezenlijking ervan, op het treffen van voorzieningen van eenvoudige aard en op de evenredigheid van de belasting. ${ }^{45}$ In tegenstelling tot de normadressaten van de WGBH/CZ kent artikel 9 IVRPH voor de Lidstaten geen uitzondering op de algemenetoegankelijkheidseis in verband met een onevenredige belasting. Voor de Lidstaten geldt deze verplichting onvoorwaardelijk. ${ }^{46}$

Zorgdragen voor een algemene toegankelijkheid kan vergaande implicaties hebben voor een aanbieder van goederen en diensten. Het ziet op 'materiële en immateriële condities, waaronder ook informatie en communi-

Zie art. 3, sub f, IVRPH, en verder uitgewerkt in artikel 9 van het Verdrag.

40. Stb. 2016, 215

41. Kamerstukken I/ 2015/16, 33990, 12

42. Kamerstukken I/ 2013/14, 33992 (R2034), 3, p. 33.

43. Zie ook Committee on the Rights of Persons with Disabilities (CRPD), General Comment 2, par. 25.

44. Kamerstukken II 2015/16, 33990, 36

45. Kamerstukken II 2015/16, 33990, 54

46. CRPD, General Comment 2, par. 25. catie' ${ }^{47}$ Naast de fysieke toegankelijkheid van gebouwen kan bij algemene toegankelijkheid ook gedacht worden aan ondersteuning op het werk, het verbeteren van de toegankelijkheid van websites, het bevorderen van bewustwording bij het personeel in bijvoorbeeld een winkel of horecagelegenheid en aan bejegening en dienstverlening. ${ }^{48}$ Uitgangspunt is dat het om eenvoudige en basale aanpassingen gaat. Dat zijn voorzieningen die weinig kosten in termen van investeringen, maar die heel snel gerealiseerd kunnen worden en weinig ingrijpend zijn. ${ }^{49}$ Alhoewel de indiener van het amendement deze afzwakking van de verplichting in artikel 2a $\mathrm{WGBH} / \mathrm{CZ}$ oorspronkelijk niet voor ogen had, is dit compromis na debat in de Tweede Kamer tot stand gekomen. De regering stond namelijk in eerste instantie niet positief tegenover het amendement. Liever dan via een wettelijke norm regelde de regering de algemene toegankelijkheid via een plan van aanpak. ${ }^{50}$

De algemenetoegankelijkheidseis is niet in de vorm van een discriminatieverbod in artikel $2 \mathrm{a}$, lid 1, WGBH/CZ opgenomen. Dit roept twee vragen op: hoe ver strekt de zorgplicht voor algemene toegankelijkheid en wie is bevoegd te beoordelen of een normadressaat zich aan zijn zorgplicht houdt? Ten aanzien van de eerste vraag heeft de regering aangegeven dat de zorgplicht verder reikt dan een streven: 'De norm bij zorg dragen is zwaarder dan de inspanningsverplichting bij streven. In geval van een inspanningsverplichting toetst een rechter over het algemeen terughoudend, minder vergaand. Echter, in het geval dat blijkt dat iemand (nagenoeg) niets doet, dus op geen enkele wijze streeft, is het mogelijk dat een rechter zich minder terughoudend opstelt en eerder oordeelt dat iemand in strijd handelt met zijn verplichting. ${ }^{51}$ Ten aanzien van de bevoegdheid rijst de vraag of het College voor de Rechten van de Mens bevoegd is te beoordelen of een aanbieder van goederen en diensten aan deze eis voldoet. Artikel $12 \mathrm{WGBH} / \mathrm{CZ}$ bepaalt immers dat het College enkel bevoegd is te onderzoeken of er sprake is van discriminatie of dat gehandeld is in strijd met artikel 2 van de wet. Artikel 2a wordt in dit laatste onderdeel niet genoemd. Echter, ook andere gelijkebehandelingswetgeving kent bepalingen die niet in een discriminatieverbod zijn vervat. Zo kennen de AWGB (artikel 8a), WGBH/CZ (artikel 9) en WGBL (artikel 10) een victimisatieverbod. Ook kent de WGBL de verplichting voor een werkgever om in een vacature te motiveren waarom hij een leeftijdseis stelt (artikel 9). Ook al beperkt de bevoegdheid van het College zich in die wetten tot het onderzoeken of er onderscheid is gemaakt (artikel 10 WCRM, artikel 14 WGBL, artikel $12 \mathrm{WGBH} / \mathrm{CZ}$ ) of dat er in strijd met de wet is gehandeld (artikel $12 \mathrm{WGBH} / \mathrm{CZ}$ ), het College heeft zich toch bevoegd geacht aan deze wetsartikelen te toetsen.

\footnotetext{
47. Kamerstukken I/ 2015/16, 33990, 34, p. 2.

48. Kamerstukken II 2015/16, 33990, 34, p. 5 en 6.

49. Kamerstukken II 2015/16, 33990, 34, p. 1-6, Handelingen II 2015/16, 36, item 10.

50. Kamerstukken II 2015/16, 33990, 34, p. 1-6.

51. Kamerstukken I/ 2015/16, 33990, 34, p. 6.
} 
Daar komt bij dat uit de wetsgeschiedenis niet blijkt dat er bij de regering of de Tweede Kamer over de bevoegdheid van het College twijfel bestaat. ${ }^{52}$ Er is zelfs een amendement aangenomen waarin is bepaald dat het College voor deze taak extra geld zou moeten krijgen. ${ }^{53}$

Ingeval het College bevoegdheid aanneemt - een vraag die het College zal moeten beantwoorden zodra een eerste klager zich na 1 januari 2017 hierover tot het College wendt - ligt er een nieuwe taak om criteria te ontwikkelen wat algemene toegankelijkheid in het individuele geval inhoudt en wanneer een normadressaat aan zijn zorgplicht heeft voldaan. Beslissingen van het Committee on the Rights of Persons with Disabilities (CRPD) in individuele klachten over de algemene toegankelijkheid kunnen hier een leidraad vormen. ${ }^{54}$ Mocht het College tot de conclusie komen dat het niet bevoegd is om de algemene toegankelijkheid te toetsen, dan moet de overheid wel zorgen voor een ander monitoring mechanism, dat sancties kan opleggen aan die partijen die nalaten op dit punt actie te ondernemen. ${ }^{55}$

Ten aanzien van de vraag wie een verzoek bij het College kan indienen over mogelijke schending van de algemenetoegankelijkheidsnorm is er een beperking: dat kan alleen door diegene die zelf benadeeld is door het handelen of nalaten van een normadressaat of door een vereniging of stichting die opkomt voor mensen met een beperking. ${ }^{56}$

\section{Conclusie}

Alhoewel de regering met de invoering van het IVRPH geen uitbreiding van rechten beoogt, is de rechtsbescherming van personen met een beperking wel degelijk toegenomen. Ook op het gebied van goederen en diensten kan thans de bescherming van de WGBH/CZ worden ingeroepen. Met name de verplichting voor normadressaten om ook op dit terrein desgevraagd doeltreffende aanpassingen te verrichten, zal bijdragen aan de inclusie van mensen met een beperking. Nog meer draagt daaraan bij de eis om zorg te dragen voor een algemene toegankelijkheid. In de nog op te stellen $\mathrm{AMvB}$ en de jurisprudentie van de rechter en het College voor de Rechten van de Mens zal nader uitgewerkt moeten worden wanneer sprake is van algemene toegankelijkheid en wanneer een normadressaat voldoende tijd heeft gehad om deze geleidelijk aan te verwezenlijken. Toch draagt deze toevoeging werkelijk bij an een verandering in denken: 'Toegankelijkheid moet normaal worden, ontoegankelijkheid wordt de uitzondering.'

\footnotetext{
52. Handelingen II 2015/16, 42, item 9, p. 32; en Kamerstukken II 2015/16, 33990, 52.

53. Kamerstukken I/ 2015/16, 33990, 52 en 59.

54. Te vinden op: www.ohchr.org. Nederland heeft overigens het Protocol bij het Verdrag, waarin het individueel klachtrecht is neergelegd, nog niet ondertekend.

55. CRPD, General Comment 2, par. 24.

56. Zie art. 10, lid 2, sub a en e, WCRM.
} 